\title{
Mechanical Properties Enhancement of Particle Reinforced Magnesium Matrix Composites Used for Hot Extruded Tubes
}

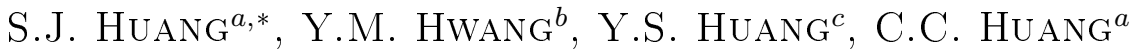 \\ ${ }^{a}$ Department of Mechanical Engineering, National Taiwan University \\ of Science and Technology, 43, Sec.4, Keelung Rd., Taipei,106, Taiwan \\ ${ }^{b}$ Department of Mechanical and Electro-mechanical Engineering, National Sun Yat-Sen \\ University, No.70, Lien-Hai Rd., Kaohsiung, Taiwan \\ ${ }^{c}$ Department of Mechanical Engineering, National Chung Cheng University, \\ 168 University Rd., Ming-Hsiung, Chia-Yi, Taiwan
}

\begin{abstract}
This paper studies new magnesium metal matrix composites ( $\mathrm{Mg} \mathrm{MMCs}$ ) reinforced with $\mathrm{SiC}$ particles by the stir-casting method for MMCs tubes hot extrusion. AZ61/SiCp MMCs' ingots reinforced with $0,0.5$ and 1 wt.\% SiC particles are fabricated by the melt-stirring technique. AZ61/SiCp MMCs' tubes are manufactured by hot extrusion using a specially designed die-set. Obvious grain size refinement both by addition of particles and extrusion process are discovered. However, the grain refinement effect caused by extrusion process is much significant than that effect caused by $\mathrm{SiC}$ particle addition. The $0.2 \%$ yield strength (YS) of extruded tubes of AZ61 and AZ61/1 wt.\% SiCp MMCs (without and with T5 treatment) are increased by $140.9-161.9 \%$ and $156.5-$ $156.7 \%$, respectively, compared with those of as-cast billets.
\end{abstract}

DOI: $10.12693 /$ APhysPolA.127.1271

PACS: 81.05.Bx, 81.20.Ev, 81.20.Hy

\section{Introduction}

Magnesium alloys metal matrix composites (Mg MMCs) reinforced with ceramic particles (such as $\mathrm{AZ61} / \mathrm{SiCp} \mathrm{MMCs}$ ) have being developed to achieve better mechanical properties and can be used as load-bearing components. Lin et al. [1] used the modified disintegrated melt deposition (DMD) technique to integrate the nano-scaled particle $\mathrm{Al}_{2} \mathrm{O}_{3}$ into AZ91D $\mathrm{Mg}$ alloy in order to form the Mg MMCs. Huang and Chen [2] studied the grain refinement of 1,2 and 5 wt.\% of $1 \mu \mathrm{m}$ AlN particles reinforced AZ91D Mg-based metal-matrix composites, and the $\beta$-phase of $\mathrm{Mg}$ was almost eliminated through homogenization. Huang et al. [3] found that the hardness, ultimate tensile strength and yield strength of $\mathrm{Mg}$ alloy (AZ80) can be improved by adding reinforcement particles (becomes AZ80 MMCs). Lim and Gupta [4] investigated the effects of extrusion temperatures on the microstructural and mechanical response of a AZ61/SiCp MMCs. Ugandhar et al. [5] investigated the effects of heat treatment on the strength and ductility of $\mathrm{AZ61} / \mathrm{SiCp}$ MMCs. Chua et al. [6] discussed the influence of $\mathrm{SiC}$ particles on the mechanical properties of $\mathrm{Mg}$ based composite with different sizes of $\mathrm{SiC}$ particles. El-Morsy et al. [7] tried to obtain grain refinement by hot extrusion and thermomechanical processing of large reduction rolling.

Few papers discussed mechanical properties of seamless extruded tube of $\mathrm{Mg}$ alloy based composites rein-

*corresponding author; e-mail: sgjghuang@mail.ntust.edu.tw forced with silicon carbide $(\mathrm{SiC})$ particles. In this paper, $\mathrm{Mg}$ AZ61 based composites reinforced with $0,0.5$ and $1 \mathrm{wt} . \% \mathrm{SiC}$ particles are fabricated by the melt-stirring technique. Seamless AZ61/SiCp MMCs tubes are manufactured by forward hot extrusion with a specially designed die-set under forming temperatures, and their mechanical properties are studied.

\section{Materials}

The matrix used in this work is magnesium alloy AZ61 containing approx. 6.0\% aluminium. Its chemical composition is shown in Table. $\mathrm{SiC}$ particles with weight fraction of $0,0.5$ and $1 \%$ within MMCs are used as the reinforcement phase. The commercially- available $\mathrm{SiC}$ powder with a particle diameter about $4.5 \mu \mathrm{m}$, density of $3.22 \mathrm{~g} / \mathrm{cm}^{3}$ and with purity of approx. $99.6 \%$ was added into AZ61 to form the Mg-based metal-matrix composites.

Chemical composition of AZ61.

TABLE

\begin{tabular}{c|c|c|c|c|c|c|c}
\hline \hline $\mathrm{Al}$ & $\mathrm{Zn}$ & $\mathrm{Mn}$ & $\mathrm{Fe}$ & $\mathrm{Si}$ & $\mathrm{Cu}$ & $\mathrm{Ni}$ & $\mathrm{Mg}$ \\
\hline 5.95 & 0.64 & 0.26 & 0.005 & 0.009 & 0.0008 & 0.0007 & Bal.
\end{tabular}

\section{Fabrication of AZ61/SiCp MMCS' ingot and its $\mathrm{T} 4$ treatment}

The fabrication of the AZ61/SiCp MMCs containing 0, 0.5 and $1 \mathrm{wt} . \%$ of $4.5 \mu \mathrm{m} \mathrm{SiC}$ particles was carried out using the melt-stirring technique. Firstly, magnesium AZ61 alloy chips accompanied with $\mathrm{SiC}$ particles were put inside the stainless crucible. $\mathrm{SF}_{6}+\mathrm{CO}_{2}$ gas started to blow 
into the stainless crucible after the heating temperature reaching $400{ }^{\circ} \mathrm{C}$ in order to avoid oxidation and burning of the magnesium alloy. The synthesis procedure involved continuously heating the magnesium AZ61 chips with $\mathrm{SiC}$ particles to $750{ }^{\circ} \mathrm{C}$ followed by stirring of the melt in the range of $450-470 \mathrm{rpm}$ for about $5 \mathrm{~min}$. The stirring was carried out using a twin blade stirrer close to the bottom of the crucible to facilitate the incorporation and uniform distribution of the $\mathrm{SiC}$ particles in the AZ61 matrix. Following stirring, the disintegrated melt slurry was deposited on a cylindrical metallic mold by removing a plug that initially blocks a hole at the bottom of the stainless crucible. The pouring process was carried out in an argon atmosphere in order to minimize oxidation of the magnesium alloy composite. AZ61/SiCp ingots with $80 \mathrm{~mm}$ in diameter and $140 \mathrm{~mm}$ height obtained by the melt-stirring process were machined to be billets with $25 \mathrm{~mm}$ inner and $64 \mathrm{~mm}$ outer diameters, respectively, and $50 \mathrm{~mm}$ height. After machining ingot, prior to extrusion process, T4 treatment (homogenization) was carried out on the billets for 10 hours at $400{ }^{\circ} \mathrm{C}$ in order to obtain best quality of extrusion.

\section{Hot extrusion and T5 treatment of AZ61 and AZ61/SiCp MMCS' Tubes}

Right after the T4 treatment, extrusion experiments of AZ61 and AZ61/SiCp MMCs' tubes were conducted using a 350 tons' extruder with single pushing cylinder. In the experiments, an initial billet temperatures, $300{ }^{\circ} \mathrm{C}$, was adopted for investigating the influence of the forming temperatures on the mechanical properties of the extruded tubes of AZ61 and AZ61/SiCp MMCs. The extrusion ratio was designed to be 14.7 , which is the ratio of the cross-sectional area of the billet to that of the tube. The ram speed was set as $1 \mathrm{~mm} / \mathrm{s}$. After extrusion, T5 treatment was carried out on tubes for 16 hours at $177^{\circ} \mathrm{C}$.

\section{Results and discussion}

\subsection{Grain size refinement}

Figure 1 shows the grain size of billet and extruded tubes with $300{ }^{\circ} \mathrm{C}$ extrusion temperature. The averaged grain sizes are measured by the linear intercept method. The tendency of the relative grain sizes of $\mathrm{AZ61} / \mathrm{SiCp}$ MMCs before and after extrusion is the same as that for AZ61. It can be observed that grain size decreased tremendously by extrusion process for any AZ61 MMCs of a fixed percentage of $\mathrm{SiC}$ addition. Besides, by virtue of $\mathrm{SiC}$ particle addition, the grain size decreases with increasing percentage of $\mathrm{SiC}$ for specific AZ61 MMCs billet and tube. It can be concluded that the grain size refinement effect caused by extrusion process is much obvious than that effect caused by $\mathrm{SiC}$ particle addition.

\subsection{Tensile test}

Specimens for tensile tests were taken from the billets and extruded tubes. The ultimate tensile strength

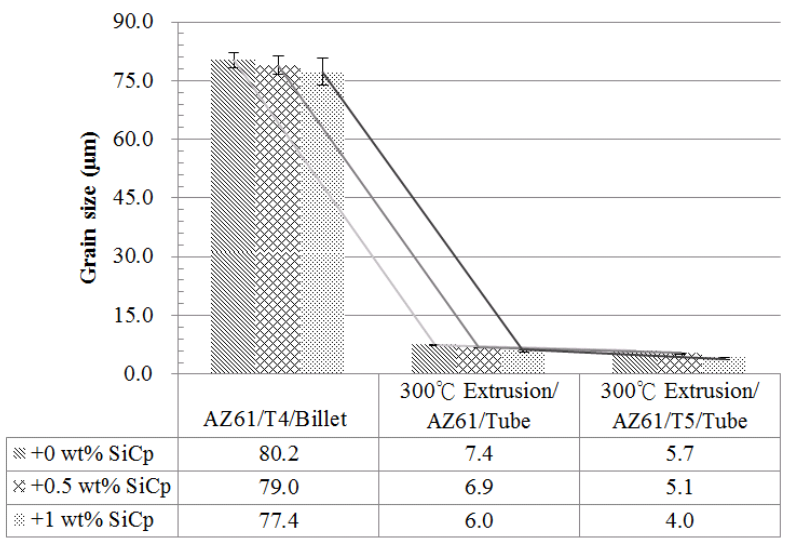

Fig. 1. Grain size of billet and extruded tube.

(UTS) of billets after T5 treatment increases with increasing percentage of $\mathrm{SiC}$ addition. The $0.2 \%$ yield strength and ultimate tensile strength of the billets and extruded tubes under different temperatures are shown in Fig. 2 and 3, respectively. From the Fig. 2-3, it is found that the ultimate tensile strength and $0.2 \%$ yield strength of AZ61/SiCp MMCs' tubes are all larger than those of AZ61 tubes. For extruded tubes with and without T5 treatment, the ultimate tensile strength and $0.2 \%$ yield strength increase with increasing percentage of $\mathrm{SiC}$ addition. Besides, that the ultimate tensile strength and $0.2 \%$ yield strength increased tremendously by extrusion process for any AZ61 MMCs of a fixed percentage of $\mathrm{SiC}$ addition. The maximum UTS 274.6 MPa and YS 156.1 MPa of AZ61/1 wt.\% $\mathrm{SiCp}$ MMCs tubes were found at the conditions of extrusion temperature $300{ }^{\circ} \mathrm{C}$ and $\mathrm{T} 5$ treatment.

It is observed that the strength of AZ61 and AZ61/SiCp MMCs extruded tubes are exceptionally bigger than those of their billets.

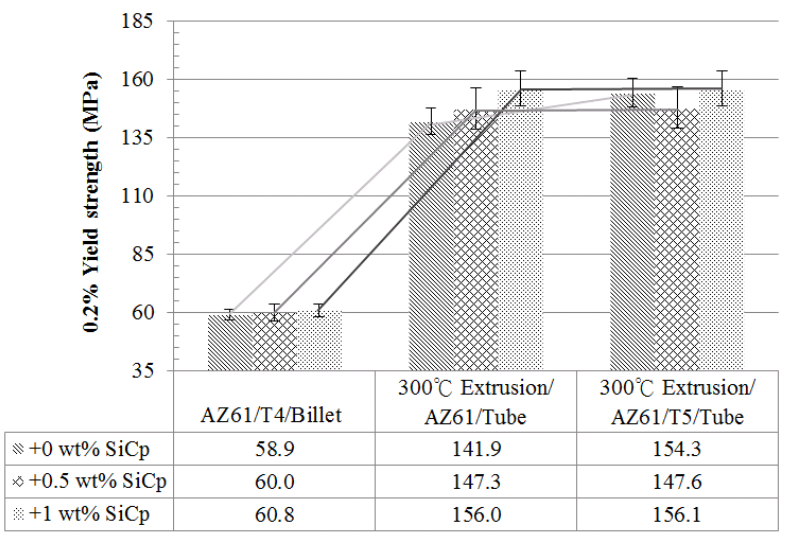

Fig. 2. Yield strength of billet and extruded tube.

The $0.2 \%$ yield strength (YS) of extruded tubes of AZ61 and AZ61/1 wt.\% SiCp MMCs (without and with T5 treatment) are increased by $140.9-161.9 \%$ and $156.5-$ $156.7 \%$, respectively, compared with those of as-cast billets. The ultimate tensile strength (UTS) of extruded 


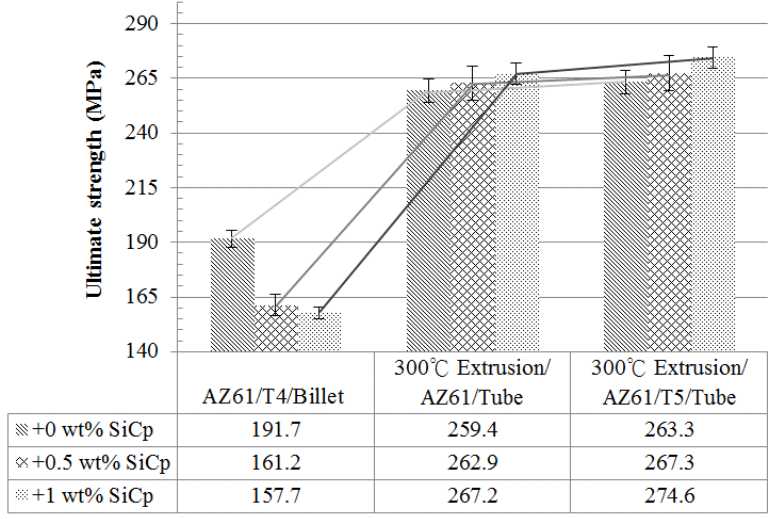

Fig. 3. Ultimate strength of billet and extruded tube.

tubes of AZ61 and AZ61/1 wt.\% SiCp MMCs (without and with T5 treatment) are increased by $35.3-37.3 \%$ and $69.4-74.1 \%$, respectively, compared with those of as-cast billets. Therefore, particle addition can strengthen the extruded AZ61 within certain amount of strength. But the strength reinforcement caused by extrusion (dynamic recrystallization) has stronger than that caused by particle addition.

\section{Conclusions}

In this paper, $\mathrm{AZ61} / \mathrm{SiCp} \mathrm{MMCs}$ reinforced with 0, 0.5 and 1 wt.\% $\mathrm{SiCp}$ were fabricated by the melt-stirring technique. Then, AZ61 and AZ61/SiCp MMCs' tubes were firstly manufactured by hot extrusion processes. Based on the experimental results, the following conclusions and some important novelties could be drawn:

The grain size refinement effect caused by extrusion process is much obvious than that effect caused by $\mathrm{SiC}$ particle addition.
A grain size less than $10 \mu \mathrm{m}$ for the extruded tube with extrusion temperature of $300{ }^{\circ} \mathrm{C}$ was obtained, which is much smaller than $84 \mu \mathrm{m}$ for the grain size of the billets.

The $0.2 \%$ yield strength and ultimate tensile strength of extruded tubes of AZ61 and AZ61/SiCp MMCs are larger than those of as-cast billets by $140.9-161.9 \%$ and $35.3-74.1 \%$ increase, respectively.

The maximum UTS 274.6 MPa and YS 156.1 MPa of AZ61/1 wt.\% SiCp MMCs tubes were obtained at the conditions of extrusion temperature $300{ }^{\circ} \mathrm{C}$ and T5 treatment.

\section{Acknowledgments}

The authors would like to extend their thanks to the National Science Council of the Republic of China under Grant no. NSC 97-2221-E-110-027-MY3 and NSC 962923-E-194-001-MY3. The advice and financial support of NSC are greatly acknowledged.

\section{References}

[1] P.Ch. Lin, S.J. Huang, P.S. Hong, Acta Metallurgica Slovaca 16, 237 (2010).

[2] S.J. Huang, Z.W. Chen, Kovove Materialy - Metallic Materials 49, 259 (2011).

[3] S.J. Huang, C.R. Li, K.L. Yan, Kovove Materialy Metallic Materials 51, 45 (2013).

[4] S.C.V. Lim, M. Gupta, Materials Research Bulletin 36, 2627 (2001).

[5] S. Ugandhar, M. Gupta, S.K. Sinha, Composite Structures 72, 266 (2006).

[6] B.W. Chua, L. Lu, M.O. Lai, Composite Structures 47, 595 (1999).

[7] A. El-Morsy, A. Ismail, M. Walyb, Materials Science and Engineering A 486, 528 (2008). 